\title{
Superior Mezenter Arter Embolisinde Erken Tanı ve Embolektomi
}

Acute Mesenteric Arterial Embolus: Early Diagnosis and Embolectomy

\author{
İbrahim AYDIN ${ }^{1}$, Ahmet Fikret YÜCEL ${ }^{1}$, Ahmet PERGEL ${ }^{1}$,Ahmet KARAKAYA ${ }^{1}$, Sabri OĞULLAR², \\ Dursun Ali ŞAHIN', Ender ÖZER ${ }^{1}$ \\ ${ }^{1}$ Recep Tayyip Erdoğan Üniversitesi Tıp Fakültesi, Genel Cerrahi AD, Rize \\ ${ }^{2}$ Recep Tayyip Erdoğan Üniversitesi Eğitim ve Araştırma Hastanesi, Radyoloji Kliniği, Rize
}

\begin{abstract}
öz
Akut mezenter arter embolisi, acil girişim gerektiren, nekroz geliştiğinde yaygın ince barsak rezeksiyonu ve sonrasında gelişen kısa barsak sendromu nedeniyle yaşam kalitesini düşüren, morbidite ve mortalitesi oldukça yüksek bir hastalıktır. Multidetektör kontrastlı BT, akut mezenterik embolinin erken tanısında oldukça önemlidir. Biz burada, kontrastlı abdominal BT ile erken tanı ve sonrasında bağırsak rezeksiyonu gerekmeden yalnızca embolektomi yaparak tedavi ettiğimiz olguyu sunmayı amaçladık.
\end{abstract}

Anahtar Kelimeler: Akut mezenter arter embolisi, multidetektör abdominal BT, embolektomi

\begin{abstract}
Acute mesenteric arterial is an emergent state that requires urgent intervention. If massive small bowel necrosis is evident not only the patient's quality of life can be worsened after short bowel syndrome due to massive small bowel resection but also it has high morbidity and mortality rate. Multidetector $\mathrm{CT}$ is a valuable tool for the evaluation of acute mesenteric arterial embolus. We present herein a case of acute mesenteric embolus which was detected with contrast-enhanced CT of the abdomen and treated with open embolectomy without resection of small bowel.
\end{abstract}

Keywords: Acute mesenteric arterial embolus, multidedector computed tomography, embolectomy 


\section{Giriş̧}

Akut mezenter iskemi (AMi) oldukça nadir görülen ve klinik olarak zor tanı konması nedeniyle morbidite ve mortalitesi yüksek bir hastalıktır. AMi, akut karın vakalarının \% 1-2'ini oluşturur (1). İnsidansı yaşlanan hasta popülasyonuna paralel olarak artmaktadır. Tanıda gecikme barsak nekrozu ile sonuçlanabileceğinden erken teşhis çok önemlidir. AMi, son yıllarda radyolojik görüntüleme yöntemlerinin daha yaygın kullanılması ile daha sık teşhis edilebilmektedir. Biz burada, kontrastlı abdominal BT ile erken tanı alan ve bağırsak rezeksiyonu gerekmeden yalnızca embolektomi yaparak tedavi ettiğimiz bir superior mezenterik arter (SMA) embolisi olgumuzu sunmayı amaçladık.

\section{OLGU SUNUMU}

Altmışaltı yaşında kadın hasta, yaklaşık bir haftadır nonspesifik karın ağrısı nedeniyle dış merkezde ayaktan takipte iken genel cerrahi polikliniğimize başvurdu. Özgeçmişinde mitral kapak darlığı mevcuttu. Antihipertansif ve asetilsalisilik asit dışında ilaç kullanma öyküsü yoktu. Hastanın yapılan fizik muayenesinde, nabız: 130/dk ve epigastriyumda derin palpasyonla ağrı dışında patoloji yoktu. Laboratuvar tetkiklerinde; laktik dehidrogenaz (LDH), kreatin fosfokinaz (CPK) ve amilaz değerleri hafif yüksekti. Takipte; karın ağrısında artış ve analjeziklere rağmen ağrıda gerileme olmaması, lökosit değerinin yükselmesi $(15.800 \mathrm{~K} / \mathrm{uL})$ nedeni ile çekilen kontrastlı BT'de; SMA'da emboli saptanması üzerine hasta acil ameliyata alındı. Gözlemde; treitz ligamanının yaklaşık $40 \mathrm{~cm}$ distalinde ince bağırsaklarda hafif renk değişikliği dışında patoloji saptanmadı (Şekil I). SMA dallarında elle nabız alınamadı. Transvers kolonun mezosu açılarak superior mezenterik ven medialinde SMA ortaya kondu. Arteriotomi yapılarak fogarty kateteri ile embolektomi işlemi yapıldı. İki adet emboli materyali çıkartıldı (Şekil II). Yeterli akımın sağlandığı görülerek arter primer onarıldı. Saniyeler içinde bağırsak renginin ve hareketlerinin geri döndüğü gözlendi (Şekil III). Postoperatif dönemde tedavi dozunda düşük molekül ağırlıklı heparin tedavisi uygulanan hasta 7.günde proflaksi tedavisi ile taburcu edildi.

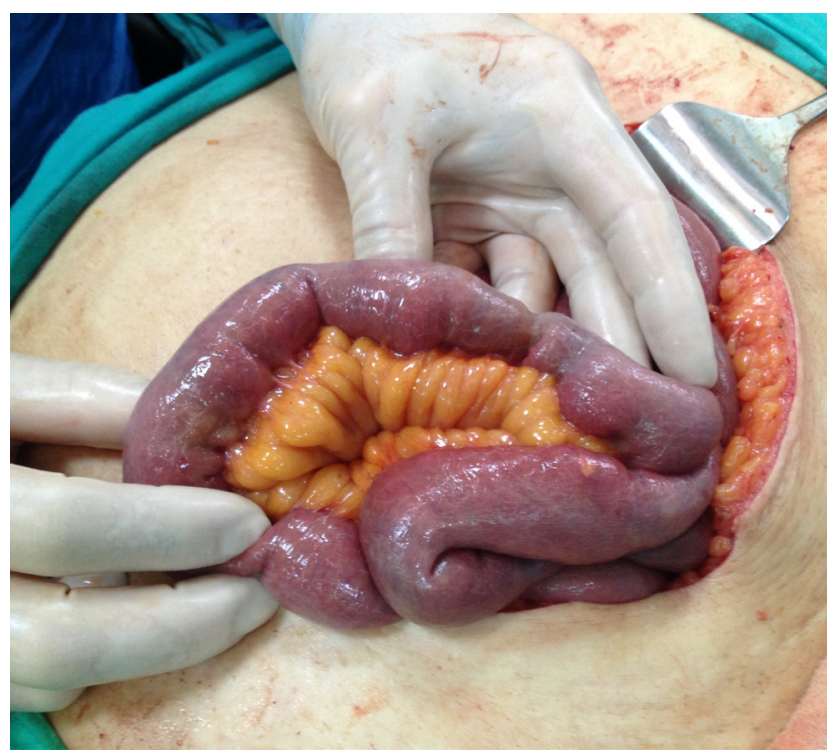

Şekil I: İnce bağırsaklarda emboliye bağlı iskemik renk değişikliği.

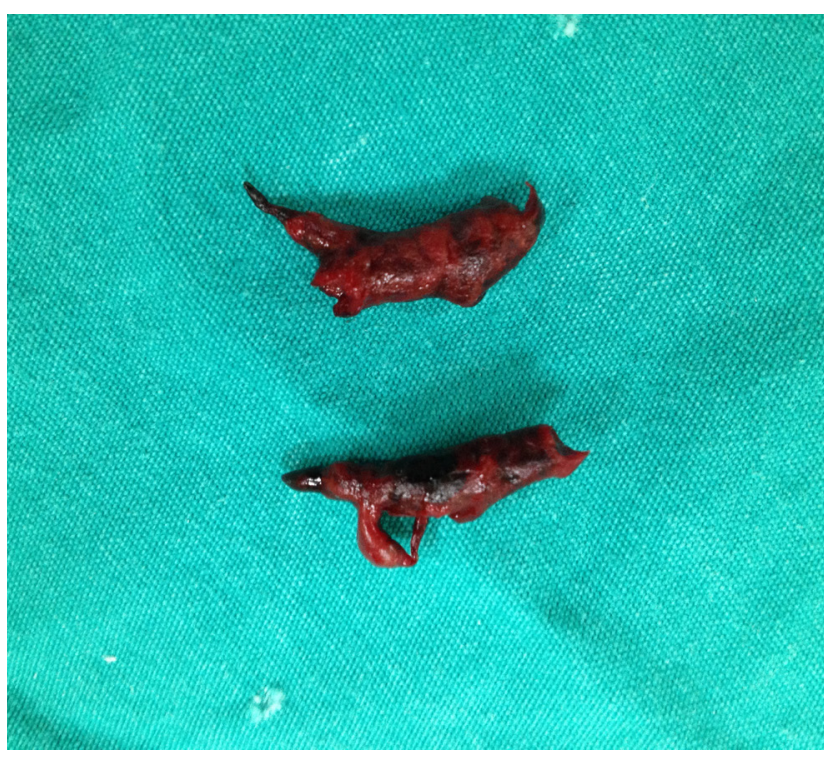

Şekil II: Embolektomi ile çıkarılan emboli materyalleri.

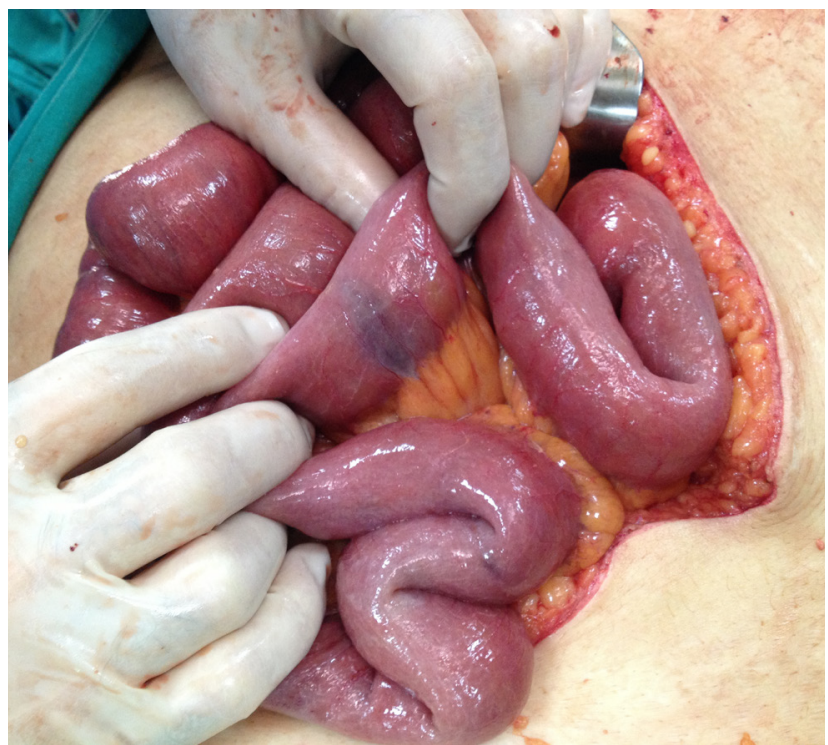

Şekil III: Embolektomi sonrası ince bağırsaklardaki iskemik değişikliklerde belirgin düzelme. 


\section{TARTIŞMA}

AMi, ilk olarak 15. yüzyılda Antonio Beniviene tarafından tanımlanmıştır (2). AMi erken tanısı zor konan nadir bir hastalık olup genellikle yaşlı hasta grubunda görülür. Toplumda yaş ortalamasının artmasına paralel olarak görülme sıklığı da artmaktadır.

AMi etiyolojisi, damar tıkanıklığının olup olmamasına bağlı olarak okluziv ve nonokluziv olmak üzere ikiye ayrılarak sınıflandırılır. Bunlar içinde en sık oklüziv tip olup bu grupta en sık neden mezenter embolidir (\%40-50). Diğer nedenler SMA trombozu (\%20-25), nonokluziv mezenterik iskemi (\%20) ve mezenterik venöz trombozdur (\%5) (3- 6). Akut SMA embolisi çoğunlukla atriyal fibrilasyon, miyokard infarktüsü, mural trombus ve mitral darlık sonucu gelişir. Olgumuzda nedenin mitral darlığa bağlı tedavi edilmemiş atriyal fibrilasyon olduğu düşünüldü.

AMi'de fizik muayene bulguları nonspesifik olup pankreatit, akut divertikülit, ince bağırsak obstruksiyonu ve akut kolesistit gibi diğer batın içi patolojilere benzerlik gösterir. Genellikle hastalarda muayene bulguları ile uyumlu olmayan şiddetli karın ağrısı yakınmaları vardır. Laboratuvar testlerinde lökosit, LDH, CPK ve amilaz düzeylerinde yükseklik görülebilse de bu bulgular spesifik değildir. Bu nedenle hastaların tanı ve tedavisinde gecikmeler olmaktadır. Erken dönemde düz karın grafisinin tanıda değeri yoktur. Geçmişte anjiyografi, AMi teşhisinde altın standart kabul ediliyordu. Ancak günümüzde anjiyografi, multidetektör BT teknolojisindeki gelişmeler nedeni ile daha çok seçilmiş vakalarda kullanılmaktadır. BT, AMi tanısında önemli rol oynar ve duyarlılığı \%94-96 oranında rapor edilmektedir $(7,8)$. AMI'de BT bulguları olarak; bağırsakta artmış duvar kalınlığı, pnömatozis intestinalis, dilatasyon ve bağırsak duvarı kontrast madde tutulumunda azalma sayılabilir (9). Hastamıza dış merkezlerde, 4 gün kadar devam eden nonspesifik karın ağrısı nedeniyle BT dışında tüm tetkikler yapılmıştı. Ancak erken dönemde bulgu saptanamadığından medikal tedavi ile takip edilmişti. Ağrının karakterinde değişiklik ve şiddetinde artma olmasına rağmen fizik muayene bulgularında belirgin değişiklik olmaması üzerine hastaya kontrastlı abdominal BT çekilerek. SMA'da emboli saptandı.
Böylece acil olarak ameliyata alınan hastanın, bağırsak rezeksiyonuna gerek kalmadan sadece embolektomi yapılarak tedavisi gerçekleştirildi. 4 gün geçmesine rağmen hastada nekroz gelişmemesi SMA'de kısmi obstruksiyona bağlandı. SMA'da akut tromboembolik nedenlere bağIı olarak tıkanıklık gelişmesi ciddi morbidite ve mortalitesi olan bir durumdur. Tıp alanında tüm ilerlemelere rağmen yatan hastalarda, SMA embolisine bağlı mortalite oranı \%59-93 gibi oldukça yüksektir $(4,5)$. Sonuç olarak; akut mezenter arter embolisine bağlı gelişen AMi, olgumuzda olduğu gibi erken tanı ve acil cerrahi girişim ile bağırsak rezeksiyonuna gerek kalmadan tedavi edilebilir. Böylece genellikle yüksek morbidite ve mortalite oranına sahip kötü prognozlu bu hastalıkta erken embolektomi ile hem bu oranlar azaltılırken hem de hastanın yaşam kalitesinde belirgin iyileşme sağlanabilir.

\section{KAYNAKLAR}

1. Yang HJ, Cho YK, Jo YJ, Jung YY, Choi SA, Lee SH. Successful recanalization of acute superior mesenteric artery thrombotic occlusion with primary aspiration thrombectomy. World J Gastroenterol 2010;16(32):4112-4.

2. Boley SJ, Brandt LJ, Sammartano RJ. History of mesenteric ischemia. The evolution of a diagnosis and management. Surg Clin North Am 1997;77(2):275-88.

3. Heys SD, Brittenden J, Crofts TJ. Acute mesenteric ischaemia: the continuing difficulty in early diagnosis. Postgrad Med J 1993;69(807):48-51.

4. Barakate MS, Cappe I, Curtin A, Engel KD, Li-Kim-Moy J, Poon MS, Sandeman MD. Management of acute superior mesenteric artery occlusion. ANZ J Surg 2002;72(1):25-9.

5. Björck M, Acosta $S$, Lindberg $F$, Troëng $T$, Bergqvist $D$. Revascularization of the superior mesenteric artery after acute thromboembolic occlusion. Br J Surg 2002;89(7):923-7.

6. Berland T, Oldenburg WA. Acute mesenteric ischemia. Curr Gastroenterol Rep 2008;10(3):341-6.

7. Danse EM, Van Beers BE, Goffette $P$, et al. Acute intestinal ischemia due to occlusion of the superior mesenteric artery: detection with Doppler sonography. J Ultrasound Med 1996;15(4):323-6.

8. Klein HM, Lensing $\mathrm{R}$, Klosterhalfen $B$, et al. Diagnostic imaging of mesenteric infarction. Radiology 1995;197(1):79-82.

9. Chou CK, Mak CW, Tzeng WS, Chang JM. CT of small bowel ischemia. Abdom Imaging 2004;29(1):18-22. 